\title{
Effects of early tooth extractions on hippocampal GFAP-positive cells in aged senescence-accelerated mice
}

\author{
Mitsuo Iinuma*1, Yoko Hioki*1, Chika Kurata*1, Yukiko Ichihashi*1, \\ Yasuo Tamura*1 and Kin-ya Kubo*2 \\ *1 Department of Pediatric Dentistry, Division of Oral Structure, Function and Development, \\ Asahi University School of Dentistry \\ 1851-1 Hozumi, Mizuho, Gifu 501-0296, JAPAN \\ *2 Department of Health Care Studies, Seijoh University \\ 2-172 Fukinodai, Tokai, Aichi 476-8588, JAPAN
}

\begin{abstract}
The effects of early tooth extractions on age-associated changes in cognitive function were evaluated. Specifically, teeth were extracted at an early age in senescence-accelerated mice (SAM)P8, and the number of glial fibrillary acid protein (GFAP)-positive astrocytes and spatial perception were evaluated at young, mature, and old ages. The following results were obtained:

1. Concerning spatial perception evaluated by the Morris water maze test, the shortening of the time until the animals reached the platform was significantly slower in mature or old mice of the tooth extraction group compared with age-matched controls. However, no significant difference was noted in the rate of shortening in young mice between the tooth extraction and control groups.

2. The number of GFAP-positive cells was significantly higher in the CA3 region of the hippocampus in the mature or old mice of the tooth extraction group compared with age-matched controls. However, no significant difference was observed in the CA1 and dentate gyrus (DG) region of the hippocampus in the mature or old mice and in the CA1, CA3, and DG region in the young mice between the two groups.

These results suggest that the loss of teeth at an early age accelerated aging and that GFAP-positive astrocytes increased to compensate for a decrease in pyramidal cells.
\end{abstract}

Key words

Early tooth extraction, Glial fibrillary acid protein (GFAP)-positive astrocytes, Hippocampus,

Morris water maze test, Senescence-accelerated mice (SAMP8)

\section{Introduction}

Some studies have indicate that aging and tooth loss promote not only changes in oral structures such as the jaw and temporomandibular joint ${ }^{1)}$ but also Alzheimer's disease ${ }^{2)}$ and dementia ${ }^{3)}$, and that such a loss of teeth is a risk factor for these disorders. Also, changes in the hippocampus induced by the loss of teeth resemble those associated with aging, and an elevation of the plasma glucocorticoid (GC) level ${ }^{4)}$, a decline in spatial memory ${ }^{5,6)}$, and decreases in the number of neurons in the hippocampus ${ }^{4,7)}$,

Received on April 2, 2010

Accepted on August 13, 2010 acetylcholine release ${ }^{3)}$, and number of c-Fos proteinpositive cells linked to learning tests ${ }^{8)}$ have been reported. In addition, astrocytes positive for glial fibrillary acid protein (GFAP), which is produced as an intermediate filament protein, have been reported to show a compensatory increase with a decrease in pyramidal cells and to be an index of aging ${ }^{9-11)}$. However, these findings have been obtained by extracted teeth at young, mature, or old ages to evaluate its effects after extractions soon. In this study, therefore, we extracted teeth from young senescenceaccelerated mice (SAM)P8 shortly after eruption, maintained the animals until mature or old ages, and examined whether the long-term absence of teeth induces functional and morphological changes in the 
hippocampus. Specifically, the Morris water maze test was performed for functional evaluation to examine the effect of an early loss of teeth on spatial memory. Also, the number of GFAP-positive astrocytes in the hippocampus was examined to evaluate the morphological effects of tooth extractions.

\section{Materials and Methods}

Sixty male SAMP8 were used in the study. The strain was kindly donated by the institute of Frontier Medical Sciences, Kyoto University. For breeding, brother-sister mating was performed in the animal room of the Central Research Division, School of Dentistry, Asahi University. The SAMP8 mouse has a median life span of 12 months and begins to show deficits in learning and memory 6 months after birth. A detailed description of the features of this strain has been given by Hosokawa et al. ${ }^{12}$ ) The animals were bred and maintained under conventional conditions; housed in groups of 5 in plastic cages $(175 \mathrm{~W} \times 245 \mathrm{D} \times 125 \mathrm{H} \mathrm{mm})$ under temperature $\left(23 \pm 1{ }^{\circ} \mathrm{C}\right)$, humidity $(55 \pm 2 \%)$, and light $(12 \mathrm{~h}$; light period, 6:00-18:00; dark period, 18:00-6:00) controlled conditions; and water were given ad libitum. This experiment was conducted according to the Animal Experiment Guidelines established by Asahi University.

\section{Tooth extraction procedure}

The mice were separated from the dams 4 weeks after birth. At 1 month after birth, 30 mice were anesthetized with sodium pentobarbital (Nembutal ${ }^{\circledR}$, Dainihonseiyaku Co., Ltd., Osaka, $30 \mathrm{mg} / \mathrm{kg}$ intraperitoneal injection), fixed in the supine position, and the upper molar teeth on both sides were extracted using an excavator as carefully as possible to minimize bleeding (extraction group). The other 30 mice underwent the same anesthesia without surgery and served as controls (control group). Following surgery solid food $\left(\mathrm{CE}-2^{\circledR}\right.$, Japan Clea Co., Ltd.) was given and the mice were maintained for 1 week (young group), 4 months (mature group), and 8 months (old group).

\section{Morris water maze test}

The Morris water maze test is a sensitive behavioral assay for hippocampal abnormalities ${ }^{5,6}$. At 1 week (young group), 4 months (mature group), and 8 months (old group) after surgery, Morris water maze test was performed as described previously ${ }^{13-15}$.
Briefly, a stainless steel tank $(90 \mathrm{~cm}$ in diameter, $30 \mathrm{~cm}$ deep) was filled with water (approximately $28^{\circ} \mathrm{C}$ ) to a height of $22 \mathrm{~cm}$ and the water surface was covered with floating polystyrene foam granules (approximately $2 \mathrm{~mm}$ in diameter). A platform $(12 \mathrm{~cm}$ in diameter) was submerged $1 \mathrm{~cm}$ under the water surface and located at a constant position near the center of one of the four quadrants of the pool. Training consisted of 28 trials over 7 days (4 trials per day, approximately 5-min intertrial interval). For each trial, the mice were placed into the water from one of four points at the perimeter of the tank. The sequence of the starting positions was randomized daily. A CCD video camera linked to a computer system (Move-tr/2D, Library Co., Ltd., Tokyo, Japan) was used to measure the latency of each mouse to reach the platform. On the test day $6,2 \mathrm{~h}$ after the maze test, a visible probe test (four trials per animal) was also carried out on all animals, as described previously ${ }^{10)}$, in which the hidden platform was replaced by a block platform extending $1 \mathrm{~cm}$ above the water and bearing a small flag with a painting of an orange ball.

\section{Morphological analysis}

For immunohistochemical analysis of GFAP induction in the hippocampal formation, all mice were subjected to the normal water maze learning test on the final test day (day 7). Each mouse was then anesthetized with sodium pentobarbital $(30 \mathrm{mg} / \mathrm{kg})$ and perfused transcardially with $30 \mathrm{~m} l$ of saline at $37^{\circ} \mathrm{C}$, followed by $100 \mathrm{ml}$ of $4 \%$ paraformaldehyde in $0.1 \% \mathrm{M}$ phosphate buffer (PB), $\mathrm{pH} 7.4$ and $0.1 \%$ glutaraldehyde. The brain was then removed and placed in $2 \%$ paraformaldehyde fixative overnight at $4{ }^{\circ} \mathrm{C}$. After rinsing with $\mathrm{PB}$ for $72 \mathrm{~h}$ at $4^{\circ} \mathrm{C}$, tissue sections $(40 \mu \mathrm{n}$ thick) were prepared on a microslicer (DTK-1000W, Dosaka, Kyoto, Japan), and floating sections were processed through a standard immunohistochemical procedure using the ABC method. The slices were first rinsed with phosphate-buffered saline (PBS), then incubated with $1 \% \mathrm{H}_{2} \mathrm{O}_{2}$ for $10 \mathrm{~min}$ at room temperature (RT), rinsed with PBS, and incubated for $60 \mathrm{~min}$ at RT with $5 \%$ normal serum. After rinsing with PBS, the sections were incubated with rabbit polyclonal anti-GFAP antiserum (Santa Cruz Biotechnology, Santa Cruz, CA) diluted 1:200 in PBS containing 0.1\% Triton X-100 (PBS-T) for $48 \mathrm{~h}$ at $4^{\circ} \mathrm{C}$, rinsed with PBS, incubated with biotinylated goat anti-rabbit IgG (Dako Cytomation, Glostrup, Denmark) diluted 1:500 in 
(A)

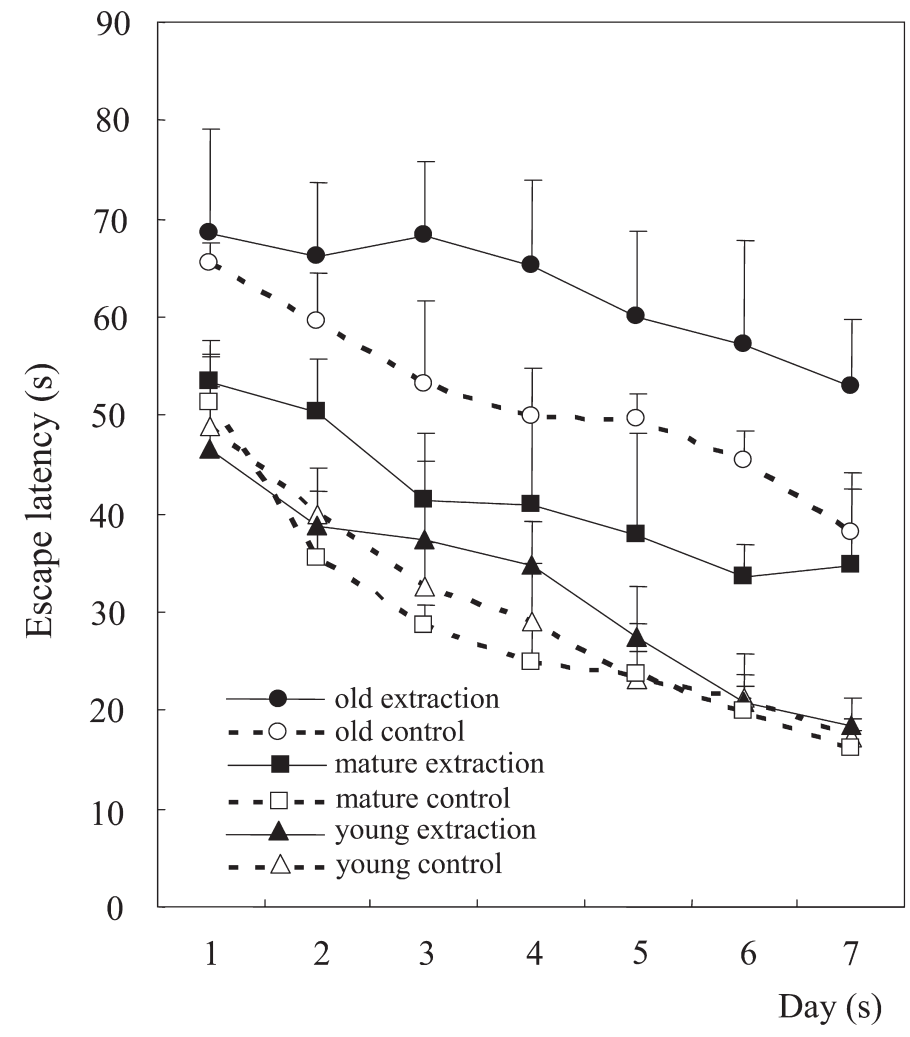

(B)

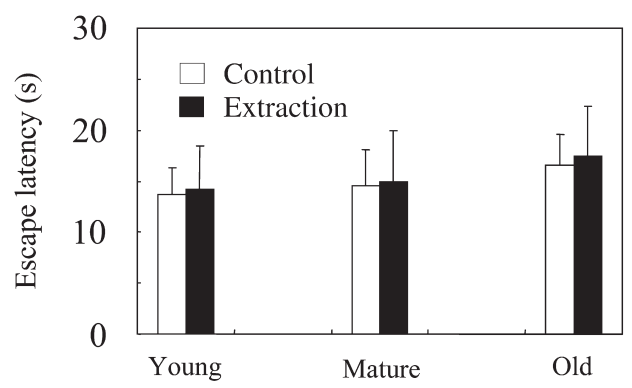

Fig. 1 (A) Spatial learning in the water maze test. The results are expressed as the mean score (mean \pm SE, $\mathrm{n}=5$ for each group) of four trials per day. Note the decrease in the time to reach the platform was significantly smaller in the mature or old tooth extraction groups than in their age-matched controls, but there was no significant difference between the young tooth extraction and control groups.

(B) Visible probe test. (mean $\pm \mathrm{SE}, \mathrm{n}=5$ for each group). Note there was no significant difference between all groups.

PBS for $2 \mathrm{~h}$ at RT, rinsed with PBS and $0.05 \mathrm{M}$ Tris-HCl buffer, pH 7.6 (TBS) and incubated with peroxidase-conjugated streptavidin (Dako Cytomation Glostrup, Denmark) diluted 1:500 with TBS for $1 \mathrm{~h}$ at RT. Bound complex was visualized using $3,3^{\prime}$-diaminobenzidine $(0.5 \mathrm{mg} / \mathrm{ml})$, nickel sulfate $(5 \mathrm{mg} / \mathrm{ml})$ and hydrogen peroxide $(0.01 \%)$ in TBS. Control sections were treated with non-immune rabbit immunoglobulin instead of primary antibody.

Quantitative analysis of the staining of GFAPpositive cells was performed, as previously described ${ }^{16)}$.
Briefly, GFAP-positive cells were counted in the left hippocampus (Bregma: $-2.18 \mathrm{~mm}$, using the atlas of Franklin and Paxinos ${ }^{17)}$, on five sections per animal using a $20 \times$ microscope objective. For each section, in a double-blind comparison, all labeled cells were counted on a stratum pyramidal length of $280 \mu \mathrm{m}$ (diagonal of a $200 \times 200 \mu \mathrm{m}^{2}$ ) in two zones each of the CA1, CA3 and dentate gyrus (DG). The data from these zones were pooled and the mean value for each subfield estimated and expressed as number of cells $/ \mathrm{mm}^{2}$. 


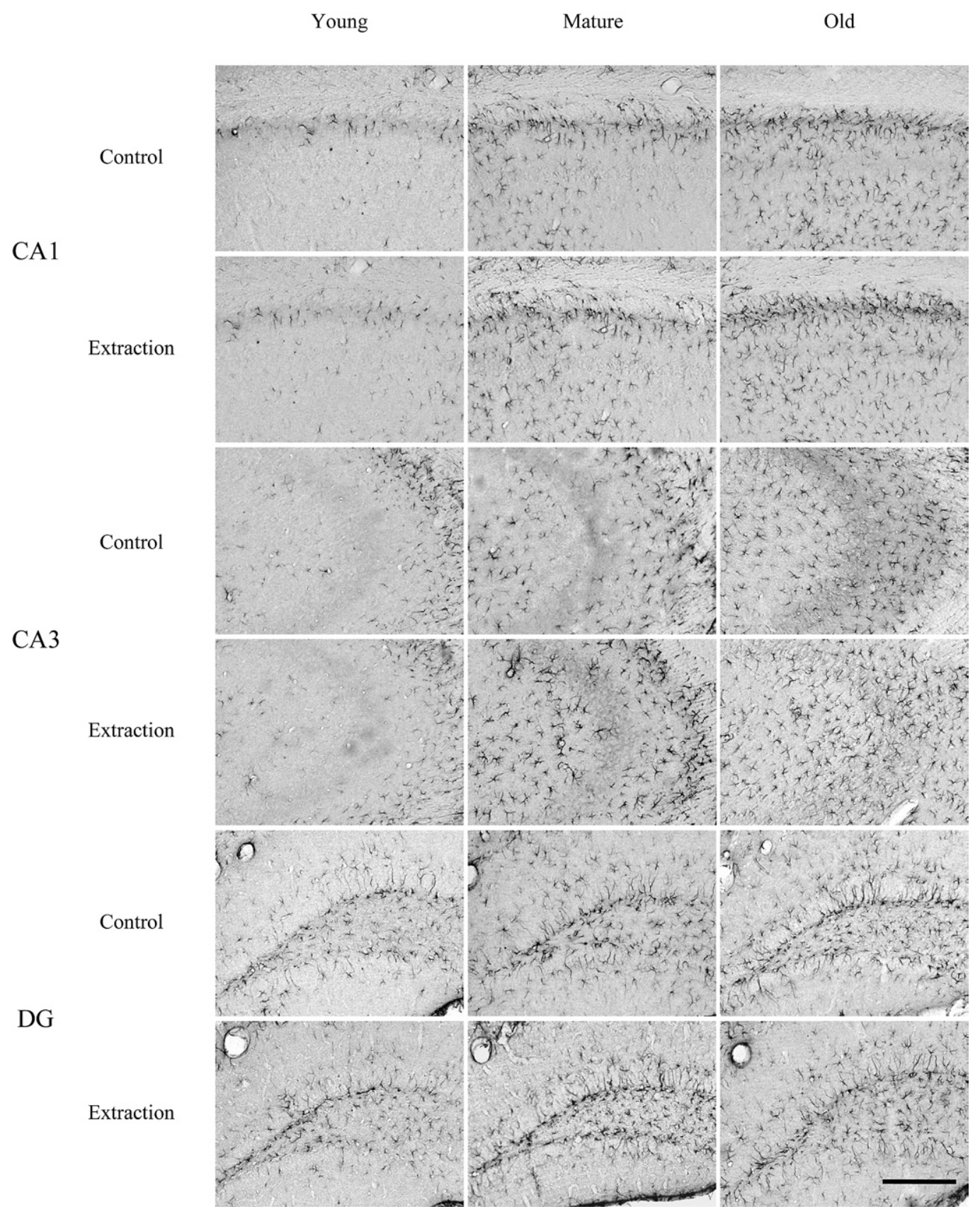

Fig. 2 Photomicrographs showing GFAP-positive astrocytes in the hippocampal CA1, CA3 and dentate gyrus (DG) subfield of control and extraction mice. Bar $200 \mu \mathrm{m}$. Note in young control and tooth extraction mice, the most frequently observed type of GFAP-positive cell had long, fine, delicate processes. In contrast, in mature and old tooth extraction mice, cellular hypertrophy of GFAP-positive cells was seen which increased with age.

\section{Statistical procedure}

The data were statistically processed by analysis of variance and, then, by Scheffe's or Turkey's multiple comparison procedure. A $P$ value of less than 0.05 was considered statistically significant.

\section{Results}

\section{Morris water maze test}

The results of the Morris water maze test for the tooth extraction and control groups are shown in Fig. 1. The time required to reach the platform decreased with repeated trials regardless of age or 


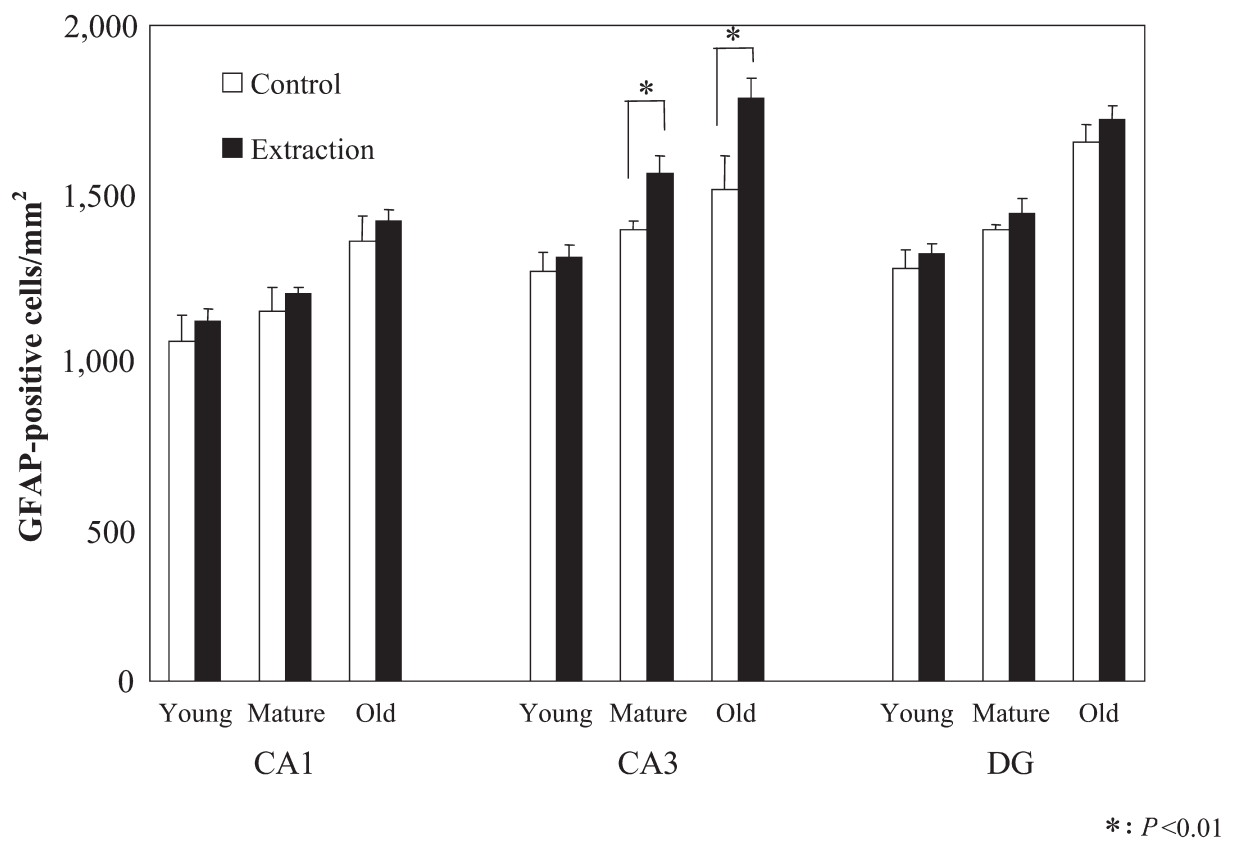

Fig. 3 Effects of the extraction condition on the number of GFAP-positive astrocytes in the hippocampal CA1, CA3 and dentate gyrus (DG) subfield. Note GFAP-positive astrocytes were significantly increased in the CA3 region of the hippocampus in the mature or old mice of the tooth extraction group, compared with the age-matched controls. No significant difference was noted in the CA1 or DG region. In the young mice, no significant difference was observed in any region between the tooth extraction and control groups.

group $[F(144,6)=27.939, P<0.0001]$, and significantly increased with an increase in age $[F(144,2)$ $=23.057, P<0.0001]$. The decrease in the time to reach the platform was significantly smaller in the mature or old tooth extraction groups than in their age-matched controls $[F(6,144)=27.886, P<0.05]$, but there was no significant difference between the young tooth extraction and control groups. There was no significant difference between all groups in the visible probe test.

\section{Immunohistochemical staining}

Figure 2 shows the results of immunohistochemical staining for GFAP-positive astrocytes in the tooth extraction and control groups. In young control and tooth extraction mice, the most frequently observed type of GFAP-positive cell had long, fine, delicate processes. In contrast, in mature and old tooth extraction mice, cellular hypertrophy of GFAPpositive cells was seen which increased with age. Figure 3 shows the numbers of GFAP-positive astrocytes in three different subfields. The number of GFAP-positive astrocytes increased with age in the 3 hippocampal regions in both the tooth extraction and control groups [CA1: $F(2,294)=107.6687$,
$P<0.0001$, CA3: $F(2,294)=6.5999, P<0.0001$, DG: $F(2,294)=174.4385, P<0.0001]$. On turkey's multiple comparisons, GFAP-positive astrocytes were significantly increased in the CA3 region of the hippocampus in the mature or old mice of the tooth extraction group, being $88 \%$ and $84 \%$, respectively, compared with the age-matched controls $(P<0.01)$. No significant difference was noted in the CA1 or DG region. In the young mice, no significant difference was observed in any region between the tooth extraction and control groups.

\section{Discussion}

In our previous study ${ }^{18)}$, pyramidal cells were markedly reduced in the CA3 region in old mice of the tooth extraction group compared with agematched controls. If neurons are reduced due to nerve injury in the central nervous system including the hippocampus, astrocytes repair and supplement cells to compensate ${ }^{1920)}$. We, therefore, counted astrocytes positive for GFAP, which is an astrocytespecific protein used as an index of age-associated change ${ }^{21-23)}$. GFAP is an intermediate filament protein $^{24)}$ that constitutes the cytoskeleton of glia cells 
such as astrocytes and is a protein that usually exists in cytoplasm as soluble polymers ${ }^{25}$. Stress and aging have been shown to induce gliosis in the central nervous system, particularly the hippocampus ${ }^{9,11,16)}$. In normal aging, also, glial activation is observed as an important physiologic reaction related to the repair of damaged brain tissues ${ }^{26,27}$. The increase in GFAP-positive astrocytes observed in this study is considered to be a mechanism to compensate for the loss of hippocampal neurons. The increase in astrocytes was also in agreement with the decline of spatial perception observed in the Morris water maze test, and the early loss of teeth was suggested to have accelerated age-associated changes. We have also confirmed a similar marked increase in GFAPpositive astrocytes in the hippocampus of bite-raised mice ${ }^{11}$. Although we did not perform morphological evaluation in this study, the hypertrophy and hyperplasia of astrocytes have been shown to be induced by nerve injury of the central nervous system, so that astrocytes may compensate for the loss of neurons in size as well as number ${ }^{10)}$. Candy ${ }^{28)}$ also reported a marked increase in astrocyte activity by blocking action potentials in the afferent nerves. Therefore, the increase in GFAP-positive astrocytes may be explained by a decrease in c-Fos proteinpositive cells due to the early loss of teeth, causing a decrease in afferent action potentials and a consequent decrease in the electrical activities of neurons. The c-fos gene and the corresponding protein Fos, which are thought to be involved in processes related to neural plasticity, and considered markers of neuronal plasticity, are considered markers of neuronal activity generated in the brain following different stimuli (spatial learning, pain, occlusion et al. ${ }^{29)}$. The expression of c-fos is rapidly and transiently induced in the hippocampus formation following training on an odor discrimination task ${ }^{30}$.

The effect of tooth extraction on GFAP-positive astrocytes number was observed only in the CA3 region and not in the CA1 and DG regions. Glutamic acid, an excitatory neurotransmitter released from mossy fiber terminals projecting from DG to CA3, is reportedly involved in changes in the GFAP-positive astrocytes in the CA3 region ${ }^{31)}$. Glucocorticoid promotes the release of glutamic acid. Increases in glucocorticoid levels and in the release of excitatory amino acids are speculated to act synergistically as neurotoxins to induce neuronal death in the CA3 region $^{32)}$.

\section{Conclusion}

In senescence-accelerated mice, early tooth extractions induced a decline in spatial memory and an increase in GFAP-positive astrocytes at mature and old ages. These results suggest that the early loss of teeth promotes aging.

\section{Acknowledgment}

This study was supported by a grant-in-Aid for Scientific Research (No. 20592420) from the Ministry of Education, Science, Sports and Culture in Japan, 2008-2011.

\section{References}

1) Marzooq, A.A., Yatabe, M. and Ai, M.: What types of occlusal factors play a role in temporomandibular disorders...? A literature review. J Med Dent Sci 46 (3): 111-116, 1999.

2) Kondoh, K., Niino, M. and Shido, K.: A case-control study of Alzheimer's disease in Japan-significance of life-style. Dementia 5: 314-326, 1994. (in Japanese)

3) Kato, T., Usami, T., Noda, Y., Hasegawa, M., Ueda, M. and Nabeshima, T.: The effect of the loss of molar teeth on spatial memory and acetylcholine release from the parietal cortex in aged rats. Behav Brain Res 83: 239-242, 1997.

4) Onozuka, M., Watanabe, K., Fujita, M., Tonosaki, K. and Saito, S.: Evidence for involvement of glucocorticoid response in the hippocampal changes in aged molarless SAMP8 mice. Behav Brain Res 131: 125-129, 2002.

5) Morris, R.G.M.: Development of a water-maze procedure for studying spatial learning in the rat. J Neurosci Methods 11: 47-60, 1984.

6) Skelton, R.W. and McNamara, R.K.: Bilateral knife cuts to the perforant path disrupt spatial learning in the Morris water maze. Hippocampus 2: 73-80, 1992.

7) Onozuka, M., Watanabe, K., Mirbod, S.M., Ozono, S., Nishiyama, K., Karasawa, N. and Nagatsu, I.: Reduced mastication stimulates impairment of spatial memory and degeneration of hippocampal neurons in aged SAMP8 mice. Brain Res 826: 148-153, 1999.

8) Watanabe, K., Ozono, S., Nagasaki, S., Saito, S., Tonosaki, K., Fujita, M. and Onozuka, M.: The molarless condition in aged SAMP8 mice attenuates hippocampal Fos induction linked to water maze performance. Behav Brain Res 128: 19-25, 2002.

9) Watanabe, K., Tonosaki, K., Kawase, T., Karasawa, N., Nagatsu, I., Fujita, M. and Onozuka, M.: Evidence for involvement of dysfunctional teeth in the senile process in the hippocampus of SAMP8 mice. Exp Gerontol 36: 283-295, 2001. 
10) Onozuka, M., Watanabe, K., Nagasaki, S., Jiang, Y., Ozono, S., Nishiyama, K., Kawase, T., Karasawa, N. and Nagatsu, I.: Impairment of spatial memory and changes in astroglial responsiveness following loss of molar teeth in aged SAMP8 mice. Behav Brain Res 108: 145-155, 2000.

11) Ichihashi, Y., Arakawa, Y., Iinuma, M., Tamura, Y., Kubo, K., Iwaku, F., Takahashi, T., Karasawa, N., Nagatsu, I. and Onozuka, M.: Changes in GFAPimmunoreactive astrocytes induced by the bite-raised condition in aged SAMP8 mice. Biogenic Amines 22: 39-48, 2008.

12) Hosokawa, M., Abe, T., Higuchi, K., Shimakawa, K., Omori, Y., Matsushita, T., Kogishi, K., Deguchi, E., Kishimoto, Y., Yasuoka, K. and Takeda, T.: Management and design of the maintenance of SAM mouse strains; an animal model for accelerated senescence and age-associated disorders. Exp Gerontol 32: 111116, 1997.

13) Kubo, K., Ichihashi, Y., Iinuma, M., Iwaku, F., Tamura, Y. and Onozuka, M.: Involvement of glucocorticoid response in hippocampal activities in aged SAMP8 mice with occlusal disharmony. Biogenic Amines 21 (5): 273-282, 2007.

14) Kubo, K., Iwaku, F., Arakawa, Y., Ichihashi, Y., Iinuma, M., Tamura, Y., Karasawa, N., Nagatsu, I., Sasaguri, K. and Onozuka, M.: The corticosterone synthesis inhibitor metyrapone prevents bite-raising induced impairment induced of hippocampal function in aged senescence-accelerated prone mice (SAMP8). Biogenic Amines 21 (6): 291-300, 2007.

15) Kubo, K., Yamada, Y., Iinuma, M., Iwaku, F., Tamura, Y., Watanabe, K., Nakamura, H. and Onozuka, M.: Occlusal disharmony induces spatial memory impairment and hippocampal neuron degeneration via stress in SAMP8 mice. Neurosci Lett 414: 188-191, 2007.

16) Onozuka, M., Watanabe, K., Nagasaki, S., Jiang, Y., Ozono, S., Nishiyama, K., Kawase, T., Karasawa, N. and Nagatsu, I.: Impairment of spatial memory and changes in astroglial responsiveness following loss of molar teeth in aged SAMP8 mice. Behav Brain Res 108: 145-155, 2000.

17) Franklin, K.B. and Paxinons, K.B.J.: The Mouse Brain in Stereotaxic Coordinates. Academic Press, New York, 1996, p. 49.

18) Hioki, Y., Iinuma, M., Kurata, C., Ichihashi, T., Tamura, Y. and Kubo, K.: Effects of early tooth loss on the hippocampus in senescence-accelerated mice. Ped Dent J 19: 196-205, 2009.

19) Viale, G., Gambacorta, M., Coggi, G., Dell'Orto,
P., Milani, M. and Doglioni, C.: Glial fibrillary acidic protein immunoreactivity in normal and diseased human breast. Virchows Arch A Pathol Anat Histopathol 418: 339-348, 1991.

20) O'Callaghan, J.P. and Miller, D.B.: The concentration of glial fibrillary acidic protein increases with age in the mouse and rat brain. Neurobiol Aging 12 (2): 171-174, 1991.

21) Eng, L.F. and Ghirnikar, R.S.: GFAP and astrogliosis. Brain Pathology 4: 229-237, 1994.

22) Landfield, P.W., Rose, G., Sandles, L., Wohlstandter, T.C. and Lynch, G.: Pattern of astroglial hypertrophy and neuronal degeneration in the hippocampus of aged, memory-deficient rats. J Gerontol 32: 3-12, 1977.

23) Luine, V., Villegas, M., Martinez, C. and McEwen, B.S.: Repeated stress causes reversible impairments of spatial memory performance. Brain Res 639: 167170, 1994.

24) Steinert, P.M. and Roop, D.R.: Molecular and cellular biology of intermediate filaments. Ann Rev Biochem 57: 593-625, 1989.

25) Jalenques, I., Albuisson, E., Despres, G. and Romand, R.: Distribution of glial fibrillary acidic protein (GFAP) in the cochlear nucleus of adult and aged rats. Brain Res 686: 223-232, 1995.

26) Ikeda, K.: Brain aging and glial activation. Jpn J Geria Psy 14 (8): 977-983, 2003. (in Japanese)

27) Sugaya, K.: Glial activation and brain aging. Folia Pharmacol Jpn 118: 251-257, 2001. (in Japanese)

28) Candy, K.S., Hyson, R.L. and Rubel, E.W.: The astrocytic response to afferent activity blockade in chick nucleus magnocellularis is independent of synaptic activation, age, and neuronal survival. $J$ Neurosci 14: 5973-5985, 1994.

29) Herrera, D.G. and Robertson, H.A.: Activation of c-fos in the brain. Prog Neurobiol 83: 83-107, 1996.

30) Hess, U.S., Lynch, G. and Gall, C.M.: Changes in c-fos mRNA expression in the rat brain during odor discrimination learning: Differential involvement of hippocampal subfields CA1 and CA3. J Neurosci 15: 4786-4795, 1995.

31) Sapolsky, R.M., Uno, H., Rebert, C. and Finch, C.: Hippocampal damage associated with prolonged glucocorticoid exposure in primates. J Neurosci 10: 2897-2902, 1990.

32) Sapolsky, R.M.: Glucocorticoid, hippocampal damage and the glutamatergic synapse. Prog Brain Res 86: 13-23, 1990. 